1 RUNNING HEAD: The Independent Effect of CO-OCCURRENCE

The Assimilative Effect of Co-occurrence on Evaluation Above and Beyond the Effect of Relational Qualifiers

Tal Moran and Yoav Bar-Anan

Ben-Gurion University of the Negev, Beer-Sheva, Israel

Brian A. Nosek

University of Virginia and Center for Open Science, USA

Social Cognition, 34(5), 433-458

Author's note: Correspondence should be addressed to: Tal Moran, Department of Psychology, Ben-Gurion University of the Negev Be'er Sheva, Israel. Email: tmo@ post.bgu.ac.il. This project was supported by grants from the Israeli Science Foundation [1012/10] to Y. B.-A, and from Project Implicit Inc. and the United States - Israel Binational Science Foundation [2013214] to Y. B.-A and B.A.N.. B.A.N. is an officer of Project Implicit Inc., a nonprofit organization that provided financial and technical support to this project, and includes in its mission "To develop and deliver methods for investigating and applying phenomena of implicit social cognition, including especially phenomena of implicit bias based on age, race, gender or other factors." 
2 RUNNING HEAD: The Independent Effect of CO-OCCURRENCE

The Assimilative Effect of Co-occurrence on Evaluation Above and Beyond the Effect of Relational Qualifiers

\begin{abstract}
Evaluative Conditioning research has investigated the effect of mere stimuli cooccurrence on evaluation and found an assimilative effect - a novel stimulus acquires the valence of the co-occurring stimulus. However, most learning episodes include stimulus co-occurrence with additional relational information. For instance, viewers learn that Batman co-occurs with crime and that he fights crime. Does co-occurrence with crime increase negativity toward Batman parallel to an increase of positivity because Batman fights crime? We examined whether co-occurrence influences evaluation above and beyond the effect of relational qualifiers. We review initial supporting evidence and report five novel experiments (total $N=505$ ) that suggest that co-occurrence with affective stimuli has an assimilative effect on evaluation even when explicit relational information suggests the opposite valence. We suggest further empirical directions for studying the effects of co-occurrence versus other relational information on evaluation.
\end{abstract}

Keywords: Evaluation, Impression Formation, Attitudes, Evaluative Conditioning, Co-occurrence 
3 RUNNING HEAD: The Independent Effect of CO-OCCURRENCE

\section{The Assimilative Effect of Co-occurrence on Evaluation Above and Beyond the Effect of Relational Qualifiers}

People often encounter novel or neutral objects that co-occur with affective stimuli. A new brand may co-occur with a popular celebrity on TV and a new acquaintance may co-occur with a criminal. However, most evaluative learning episodes also include relational information that explains why the stimuli co-occur. The celebrity might report hating the new brand, and the new acquaintance might confront the criminal. The present research tested whether stimuli co-occurrence has an assimilative effect on the evaluation of the neutral object even when there is relational information suggesting the opposite valence.

\section{Theoretical Background}

Evaluative conditioning (EC, De Houwer, Thomas, \& Baeyens, 2001) refers to changes in liking due to stimulus pairing (De Houwer, 2007). In a prototypical EC study, a neutral stimulus (conditioned stimulus; CS) repeatedly occurs with a positive or a negative stimulus (unconditioned stimulus; US). The common result is an assimilative effect: the evaluation of the formerly neutral CS shifts toward the valence of the US. EC has been examined in a large number of studies (see De Houwer, Thomas, \& Baeyens, 2001; Hofmann, et. al., 2010; for a review), mostly with deliberate attempts to eliminate information about any relation that the stimuli might have, other than co-occurrence. EC research mainly investigated the procedural conditions under which co-occurrence between stimuli results in the typical assimilative effect. These conditions include the number of pairings (e.g., Baeyens, Eelen, Crombez, \& Van den Bergh, 1992), the order of stimuli presentation (e.g., Hammerl, \& Grabitz, 1993), extinction (e.g., Baeyens et al., 1988; Gast \& De Houwer, 2013; Gawronski, Gast, \& De Houwer, 2015), contingency memory (e.g., 
Bar-Anan, De Houwer, \& Nosek, 2010; Gawronski \& Walther, 2012; Hütter et al., 2012), changes in the identity or valence of stimuli (e.g., Baeyens, Eelen, Van den Bergh, \& Crombez, 1992; Walther, Gawronski, Blank, \& Langer, 2009), and many more.

EC may occur due to automatic formation of a mental representation that includes the CS and the US valence (Baeyens, Eelen, \& Crombez, 1995; Baeyens, Eelen, Crombez, \& Van den Bergh, 1992; Levey \& Martin, 1975; Martin \& Levey, $1978,1994)$. This assumption is the shared property of a few theoretical accounts that has been considered associative (De Houwer, Thomas, \& Baeyens, 2001; Hofmann, et. al., 2010; Walther, Weil, \& Langer, 2011). Although these accounts differ in their assumptions regarding how the representation of the CS-US link is formed and what the representation includes, they are all associative in that they assume that the representation that is formed includes the CS and the valence of the US and that the CS automatically activates the valence of the US.

De Houwer (2007; Mitchell, De Houwer, \& Lovibond, 2009) challenged this dominant view and suggested that EC is mediated by propositional processes. Propositional processes do not encode a CS-US link, but the specific relation between the CS and the US. De Houwer did not propose one specific account to what proposition is formed and how that proposition changes evaluation. Therefore, it might be most accurate to consider his suggestion a propositional perspective about EC rather than a propositional account for EC.

The propositional perspective inspired studies testing whether relational qualifiers moderate the effect of CS-US co-occurrence on evaluation (Fiedler \& Unkelbach, 2011; Förderer \& Unkelbach, 2012; Walther, Langer, Weil, \& Komischke, 2011; Zanon, De Houwer, Gast, \& Smith, 2014). For example, in one 
study (Fiedler \& Unkelbach, 2011) participants observed co-occurrence between pictures of neutral men (CSs) and pictures of positive or negative men (USs). In one condition, the instructions directed the participants to encode the men as friends and in the other condition to encode the men as enemies. Participants reported preference for the men who co-occurred with positive men over men who co-occurred with negative men only when they encoded the co-occurring men as friends. When they encoded the co-occurring men as enemies they showed a preference for men who cooccurred with negative men over men who co-occurred with positive men. In another study (Förderer \& Unkelbach, 2012) participants observed the co-occurrence of CSs (pictures of men) with positive (e.g., puppies) or negative (e.g., snakes) USs provided simultaneously with a relation qualifier that was either loves or loathes (e.g., $\mathrm{X}$ loathes snake). Again, the relational information reversed the preference: Participants liked targets that loathed snakes and disliked targets that loathed puppies. In another study (Zanon, De Houwer, Gast, \& Smith, 2014), participants reported more liking of nonwords (e.g., lokanta) that co-occurred with negative (e.g., ugly) than with positive words (e.g., happy) when instructions preceding the pairing procedure indicated that the meaning of each non-word was the opposite of the meaning of the co-occurring word.

Overall, these studies suggest that evaluation is sensitive to relational qualifiers between the CS and US. However, this does not preclude the possibility that mere co-occurrence has a parallel, independent assimilative effect on evaluation. For example, perhaps the information that the nonword lokanta is the opposite of the word happy pushes the evaluation of lokanta to the negative pole, and, at the same time, the co-occurrence of lokanta with happy pushes the evaluation of lokanta to the positive 
6 RUNNING HEAD: The Independent Effect of CO-OCCURRENCE

pole. In the present article, we investigate whether co-occurrence has an assimilative evaluative effect that is not overcome by relational qualifiers.

The possibility of parallel influences of co-occurrence and relation qualifiers on evaluation has theoretical and practical implications. From a theoretical standpoint, associative models are highly compatible with the possibility that co-occurrence influences evaluation above and beyond the effect of other relational information. Cooccurrence is expected to automatically form mental representation that includes the CS and the US (or the CS and the US valence). The mental representation activates the US valence when evaluating the CS.

These models were suggested for the effect of CS-US co-occurrence on evaluation, they have never been proposed as accounts for the effect of all information forms on evaluation. As such an effect of relational qualifiers on evaluation does not challenge associative models. The effect of relational information is another evaluative effect that can operate independently of the evaluative effect of the mere co-occurrence between the CS and the US. ${ }^{1}$

The propositional perspective might seem less compatible with an independent effect of co-occurrence information because propositional processes allow making inference based on specific relations. If the relational information indicates that the stimuli are opposite, why would there be a parallel assimilative effect? However, a propositional model could incorporate the assumption that the proposition the CS cooccurs with the US has an assimilative effect on evaluation, independent of other

${ }^{1}$ If, for instance, an experiment would show that the mere exposure effect (Zajonc, 1968) is stronger than the effect of co-occurrence and can reverse the evaluation of a CS that co-occurred with a negative US, the fact that the associative models cannot explain the mere-exposure effect would have no bearing on the validity of these models as accounting for the effect of co-occurrence on evaluation. 
7 RUNNING HEAD: The Independent Effect of CO-OCCURRENCE

propositions such as the CS and the US are opposites. Therefore, although an independent effect of co-occurrence on evaluation would not refute the propositional perspective, it would constrain propositional models to those that can explain why stimuli co-occurrence has an assimilative effect on evaluation even when other relational information suggests that that the stimuli are of different valence.

Obviously, it is also possible that both propositional and associative processes contribute to evaluative learning, by working in parallel, in combination, or in different contexts (Gawronski \& Bodenhausen, 2014).

Practically speaking, most evaluative learning episodes include co-occurrence between the targets object and affective stimuli, and relational information about the stimuli. This occurs when observing other people's behaviors, when learning about other people's traits, and when watching attractive people, events, or activities in spatiotemporal proximity to a product in advertisements. The latter is a prototypical example used by EC researchers. Most viewers are aware of the complex relational information the product and the attractive people were presented together for marketing purposes. If relational information easily overrides the effect of cooccurrence, then most of the existing research investigating the effect of mere cooccurrence without other explicit relational information could be irrelevant to most real life evaluative learning.

\section{Previous Evidence}

Although previous EC research did not focus on the effect of stimulus cooccurrence above and beyond the effect of relational qualifiers, it does provide results compatible with this possibility. Förderer and Unkelbach (2012) found a main effect of co-occurrence, over and above the effect of the specific relation: people reported more liking of targets that co-occurred with positive stimuli over targets that co- 
occurred with negative stimuli $(p=.009, d=0.4) .{ }^{2}$ Likewise, in a study testing the role of cognitive balance in the formation of interpersonal attitudes participants first formed impressions of individuals based on behavioral descriptions (Gawronski, Walther, \& Blank, 2005). Then, these individuals co-occurred with new individuals with the information that the known individual either likes or dislikes the new individual. Participants showed positive evaluation of targets liked by positive people and of targets disliked by negative people. Participants showed negative evaluation of targets liked by negative people and of targets disliked by positive people. However, a main effect of co-occurrence still emerged: independent of the relational qualifier (likes/dislikes), participants evaluated the new targets that co-occurred with positive known individuals more positively than targets that co-occurred with negative known individuals $\left(p<.001, \eta_{p}{ }^{2}=.25\right)$.

A possible weakness of this existing evidence is that these studies used relational qualifiers that have an affective meaning of their own (i.e., love is positive and hate is negative). Therefore, a rival account is that negative relations have a weaker effect on attitude formation than positive relations. ${ }^{3}$ Perhaps the information that someone has negative feelings toward specific objects seems less important for forming attitudes than the information that someone has positive feelings toward specific objects. This could account for why people reported more liking of men who

2 The information regarding the co-occurrence effect in Förderer and Unkelbach's research was obtained via personal communication (S. Förderer, June, 6, 2013). 3 Notice that this possible explanation does not contradict the finding that negative information is given more weight in impression formation than positive information (Skowronski \& Carlston, 1989). Dislike and hate represent negative feeling; they are not necessarily negative information about the targets. For example, the information that the target dislikes negative people is positive information. 
9 RUNNING HEAD: The Independent Effect of CO-OCCURRENCE

love positive animals than of men who loath negative animals and more disliking of men who love negative animals than of men who loath positive animals.

Evidence that does not rely on affective relations (i.e., loving and hating) comes from research that used relation qualifiers to examine the sensitivity of automatic versus deliberate evaluation to validity information (Moran \& Bar-Anan, 2013). Participants observed target characters that started or ended pleasant or unpleasant sounds. The co-occurrence between the characters that ended affective events and the events that they ended was not valid evidence that they have similar valence. Compatible with the theoretical notion that validity information has a stronger influence on deliberate evaluation than on automatic evaluation (Gawronski \& Bodenhausen, 2006), automatic evaluation was more sensitive than deliberate evaluation to the co-occurrence between the characters and the events. However, Moran and Bar-Anan (2013) also found a strong effect of co-occurrence on deliberate evaluation above and beyond the effect of the relational qualifiers $\left(\eta_{p}^{2} s=0.50,0.47\right.$, ps <.001, .001, in Experiments 1 and 2, respectively). Moran and Bar-Anan (2013) did not predict that finding and suggested that it should be studied further. A task we carry out in the present research.

To summarize, the results of existing research is compatible with the assumption that co-occurrence has an independent effect on evaluation, above and beyond the effect of other relational information. However, these results are limited. First, most of the relevant studies used relational qualifiers that have an affective meaning (e.g. loath), so it is possible that the observed results in these studies represent a weaker effect of negative relations than positive relations on attitude formation. Similarly, the reason for Moran and Bar-Anan's (2013) results could be that the relation end is weaker than the relation start in inducing attitudes for reasons 
10 RUNNING HEAD: The Independent Effect of CO-OCCURRENCE

unrelated to the fact that end pairs the target with stimuli of opposite valence. Second, it is possible that participants' impression formation task was more complicated when the relational information suggested that the valence of the target was opposite to the co-occurring valence. As a result, participants may have been less likely to infer the true valence of the targets presented with such relational information. According to this account, the main effect of co-occurring valence on deliberate evaluation could be the result of a few participants who misunderstood the task instructions, or did not pay attention to the relational information. These alternative accounts are barriers to concluding with the present evidence that co-occurrence has an independent effect on evaluation above and beyond the effect of other relational information.

\section{The Present Research}

The goal of the present investigation was to test whether co-occurrence has an effect on evaluation above and beyond the effect of relational qualifiers. We tested this assumption in Experiments 1-3 using different types of relational qualifiers. Furthermore, we added a memory measure to make sure that participants understood the relational information and remembered the valence of the behaviors that the targets performed. Unlike previous studies, we also tested the effect of co-occurrence among a subset of participants who showed strong evidence that they understood the

relational information: they remembered correctly the true valence of each target, and also demonstrated that understanding by reporting preference for the target who performed a positive action over the target who performed a negative action.

To anticipate our results, Experiments 1-3 replicated the findings we cited above, providing more evidence compatible with the assumption that co-occurrence has an effect on evaluation above and beyond the effect of relational qualifiers. Still, one might argue that all these results reflect a weaker effect of specific relational 
qualifiers on evaluation, and not a genuine effect of co-occurrence on evaluation. Perhaps the effect of co-occurrence that was found in Moran and Bar-Anan's (2013) studies reflect weaker attitude induction by the relation end than by the relation start. And, similar alternative accounts could also be proposed for the relations used in Experiments 1-3. Because this weakness is inherent in the design of previous research and of Experiments 1-3, in Experiments 4 and 5 we used a different approach for testing whether co-occurrence has an assimilative effect on evaluation that is not cancelled by contradictory relational information. Specifically, we manipulated participants' focus on the co-occurrence versus other information (the inference from the relation) and tested whether a focus on the co-occurrence would increase the assimilative effect on evaluation, despite perfect comprehension of the relational information. $^{4}$

\section{Experiments 1-3}

Participants learned about four families of creatures (CSs). Each family helped or harmed the participants (e.g., performed a positive or a negative action) through a relation with affective stimuli (USs) of a certain valence. One family helped the participants by having a relation with a positive stimulus (e.g., started a pleasant stimulus); one family helped participants by having a relation with a negative stimulus (e.g., ended an unpleasant stimulus); one family harmed the participants by having a relation with a negative stimulus (e.g., started an unpleasant stimulus); and one family harmed participants by having a relation with a positive stimulus (e.g., ended a

\footnotetext{
${ }^{4}$ We report all data exclusions, manipulations, and measures, and how we determined our sample sizes. In all experiments, decisions to stop collecting data did not depend on the obtained results. To see the materials and data of the whole project (Experiments 1-5) visit https://osf.io/v2trw/.
} 
pleasant stimulus). After learning this information, participants evaluated each family. Each experiment used a different pair of relations.

\section{Method}

Participants. Participants in Experiments 1-3 volunteered to participate on the internet at the Project Implicit research website (Nosek, 2005). Experiments 1-3 were online at the same time, but participating in one made participants ineligible to be assigned to the others. The experiments were available for participants for a weekenough time to achieve more than $95 \%$ statistical power for detecting effects considerably smaller than the co-occurrence effect found in previous research (Moran \& Bar-Anan, 2013). In all the experiments, we included only participants who completed all the dependent measures. In Experiment 1, these were 68 (65\% women, $\left.M_{\text {age }}=26.2, S D_{\text {age }}=10.3\right)$ participants, in Experiment 2, these were 39 (59\% women, $\left.M_{\mathrm{age}}=28.9, S D_{\text {age }}=11.7\right)$ participants, and in Experiment 3, these were $50(75 \%$ women, $\left.M_{\text {age }}=23.4, S D_{\text {age }}=9.7\right)$ participants. $^{5}$

\section{Materials and procedure.}

Materials. The target stimuli (CSs) were 16 drawings of alien creatures divided equally into four families (taken from Moran \& Bar-Anan, 2013). Families differed in their color (green, purple, red, and yellow) and their head shape. In Experiment 1, the positive US was a drawing of gold bars presented alongside images of puppies and smiling babies, and the negative US was a drawing of garbage piles

\footnotetext{
${ }^{5}$ The studies were removed from the website after a week because their overall completion rate $(53 \%, 157 / 296)$ was below $60 \%$, the minimum rate allowed in Project Implicit. Thus, the decision to stop data collection did not depend on the obtained results. Because the participants are volunteers, completion rate in Project Implicit tends to be low, typically $60 \%-65 \%$. We suspect that the reason for the lower completion rate in the present studies is that, unlike most studies in Project Implicit, it did not involve prejudice toward known social groups.
} 
13 RUNNING HEAD: The Independent Effect of CO-OCCURRENCE

presented alongside images of threatening dogs and crying babies. In Experiments 23 , the USs were images of puppies and cockroaches.

Learning Procedure. The experiments always started with the learning procedure. Participants played a game in which they met alien creatures from four different families and had the goal of learning what action is typical of each family. On each trial of the learning task, a creature (CS) appeared in spatiotemporal proximity to a positive or a negative stimulus (US) and performed an action that either helped or harmed the participant. The creature helped or harmed the participants by having a relation with the affective stimulus. Each creature belonged to one of the families. Participants knew in advance that each family always perform exactly the same action (e.g., gave puppies to the participant), and their task was to learn which action each family performed. The family-action match was counterbalanced between participants.

In Experiment 1, the relations were starts and ends. The four actions were starting the appearance of gold bars, starting the appearance of garbage piles, ending the appearance of gold bars, and ending the appearance of garbage piles. The creatures who started the appearance of the affective stimuli co-occurred with stimuli of one valence and their relation with those stimuli indicated they have the same valence. The creatures who ended the appearance of the affective stimuli co-occurred with stimuli of one valence but their relation with those stimuli indicated they have the opposite valence. The procedure consisted of gold trials and garbage trials. Gold trials started with the appearance for $1500 \mathrm{~ms}$ of a creature from the "start-gold" family. After the creature disappeared, the gold-bars image started appearing on the screen for a few (3 to 5; the number varied between trials) consecutive one-second presentations, separated by a blank screen for $200 \mathrm{~ms}$. The presentation of the gold 
bars ended 200ms before a member of the "end-gold" family appeared (for 1500ms). Garbage-piles trials were identical but with the garbage-piles image instead of the gold-bars image. After the appearance of an "end" creature, the screen was blank for two seconds, and then a "start" creature appeared, starting the next trial. The learning phase contained two blocks of 12 randomly ordered trials (6 gold trials and 6 garbage trials).

In Experiment 2, the relations were gives and takes. The actions were giving puppies, giving cockroaches, taking puppies away, and taking cockroaches away. The creatures who gave puppies co-occurred with stimuli of one valence and their relation with those stimuli indicated they have the same valence. The creatures who took away affective stimuli co-occurred with stimuli of one valence but their relation with those stimuli indicated they have the opposite valence. Each trial started with a one-second fixation image, followed by a three-second simultaneous presentation of a creature on the left side of the screen, a puppy or a cockroach on the right side of the screen, and the word "gives" or "takes" between them (e.g., creature gives puppy). Each family appeared 12 times (randomized trial order).

Experiment 3 replicated Experiment 2 with different relations: allows and prevents. The actions were: allow the participant to get puppies, allow the participant to get cockroaches, prevent the participants from getting puppies, and prevent the participants from getting cockroaches. Instead of "gives" and "takes," the text between the creature and the object was "allows you to get" or "prevents you from getting."

Evaluation. After the learning task, participants reported on a 6-point scale how much they liked each family of creatures ( $1=$ dislike strongly, $6=$ like strongly). 
15 RUNNING HEAD: The Independent Effect of CO-OCCURRENCE

Memory. After the evaluation, participants indicated the action each family performed during the game (in four questions: one family at a time). The response options listed the four possible actions, of which the participants chose one.

Design. The design in each experiment was 2 (co-occurring [US] valence: positive, negative; within participants) X 2 (target's [CS] role: positive [helped participants], negative [harmed participants]). In all experiments in this research, the factor target's role is the role inferred from the relational information, thus representing the effect of relational information.

\section{Results}

The upper part of Table 1 presents the evaluation scores for each target type, for each Experiment. We submitted the evaluation scores to a 2 (co-occurring valence: positive, negative) x 2 (target's role: positive, negative) ANOVA. The target's role is the valence inferred from the relational information. As expected from previous research, the relational qualifiers had a strong influence on the evaluation: There was a main effect of target's role in all three experiments: Experiment 1: $F(1$, $67)=84.55, p<.001, \eta_{p}{ }^{2}=.55,90 \%$ CI $[.42, .64]$; Experiment $2: F(1,38)=53.83, p$ $<.001, \eta_{p}{ }^{2}=.58,90 \%$ CI $[.39, .69] ;$ Experiment 3: $F(1,49)=143.38, p<.001, \eta_{p}{ }^{2}=$ $.74,90 \% \mathrm{CI}[.63, .80]$. That main effect reflected more liking of the targets that helped participants $(M s=4.68,4.77,5.08, S D s=0.98,0.97,1.07$, in Experiments 1,2 and 3, respectively), than of targets that harmed participants $(M s=2.79,2.36,2.04$, $S D s=1.23,1.28,0.99)$.

Most importantly, there was also a main effect of co-occurring valence: Experiment 1: $F(1,67)=7.25, p=.009,{ }_{\eta_{p}}{ }^{2}=.09,90 \%$ CI $[.01, .21]$; Experiment 2: $F(1,38)=8.35, p=.006,{ }_{\eta_{p}}{ }^{2}=.18,90 \% \mathrm{CI}[.03, .34] ;$ Experiment $3: F(1,49)=5.02$ $p=.029,{ }_{\eta_{p}}{ }^{2}=.09,90 \% \mathrm{CI}[.00, .23]$. That main effect reflected more liking of the 
targets that co-occurred with positive USs $(M s=3.90,3.72,3.68, S D s=0.79,0.56$, 0.54, in Experiments 1, 2 and 3, respectively) than targets that co-occurred with negative USs $(M s=3.57,3.41,3.44, S D s=0.96,0.63,0.71), d s=0.37,0.52,0.38$, in Experiments 1-3, respectively. We found a significant interaction only in Experiment $2, F(1,38)=7.14, p=.011, \eta_{p}{ }^{2}=.15,90 \%$ CI $[.02, .32]$. That interaction revealed a significant effect of co-occurring valence only when target's role was positive, $F(1$, $38)=11.00, p=.002,{ }_{\eta_{p}}{ }^{2}=.22$, and not when target's role was negative, $F(1,38)=$ $1.54, p=.222, \eta_{p}^{2}=.03$.

Table 1

Experiment 1-3: Evaluation as a function of co-occurring valence and target's role

\begin{tabular}{lccccc}
\hline $\begin{array}{l}\text { Target's role } \\
\text { Co-occurring valence }\end{array}$ & $\mathbf{N}$ & $\begin{array}{c}\text { Positive } \\
\text { Positive }\end{array}$ & $\begin{array}{c}\text { Positive } \\
\text { Negative }\end{array}$ & $\begin{array}{c}\text { Negative } \\
\text { Positive }\end{array}$ & $\begin{array}{l}\text { Negative } \\
\text { Negative }\end{array}$ \\
\hline $\begin{array}{l}\text { Experiment 1 } \\
\text { All participants }\end{array}$ & 68 & $4.87_{\mathrm{a}}(1.18)$ & $4.50_{\mathrm{b}}(1.18)$ & $2.94_{\mathrm{c}}(1.38)$ & $2.65_{\mathrm{c}}(1.54)$ \\
Perfect memory & 56 & $4.95_{\mathrm{a}}(1.23)$ & $4.59_{\mathrm{b}}(1.17)$ & $2.73_{\mathrm{c}}(1.27)$ & $2.52_{\mathrm{c}}(1.53)$ \\
Perfect comprehension & 33 & $5.39_{\mathrm{a}}(0.79)$ & $5.06_{\mathrm{b}}(0.75)$ & $2.24_{\mathrm{c}}(1.06)$ & $2.00_{\mathrm{c}}(1.06)$ \\
\hline Experiment 2 & & & & & \\
All participants & 39 & $5.21_{\mathrm{a}}(0.95)$ & $4.33_{\mathrm{b}}(1.53)$ & $2.23_{\mathrm{c}}(1.37)$ & $2.49_{\mathrm{c}}(1.50)$ \\
Perfect memory & 26 & $5.19_{\mathrm{a}}(0.98)$ & $4.46_{\mathrm{b}}(1.53)$ & $2.00_{\mathrm{c}}(1.20)$ & $2.31_{\mathrm{c}}(1.38)$ \\
Perfect comprehension & 21 & $5.33_{\mathrm{a}}(0.86)$ & $4.90_{\mathrm{b}}(1.18)$ & $1.76_{\mathrm{c}}(0.89)$ & $1.81_{\mathrm{c}}(0.98)$ \\
\hline Experiment 3 & & & & & \\
All participants & 50 & $5.28_{\mathrm{a}}(1.14)$ & $4.88_{\mathrm{b}}(1.22)$ & $2.08_{\mathrm{c}}(1.07)$ & $2.00_{\mathrm{c}}(1.26)$ \\
Perfect memory & 35 & $5.40_{\mathrm{a}}(0.95)$ & $5.00_{\mathrm{b}}(1.03)$ & $2.06_{\mathrm{c}}(0.97)$ & $1.77_{\mathrm{c}}(1.21)$ \\
Perfect comprehension & 31 & $5.52_{\mathrm{a}}(0.85)$ & $5.06_{\mathrm{b}}(1.03)$ & $1.90_{\mathrm{c}}(0.79)$ & $1.42_{\mathrm{d}}(0.67)$ \\
\hline
\end{tabular}

Notes. Target's role is the target's evaluation inferred from the relational information. Perfect comprehension: showed perfect memory and also evaluated each of the two families that helped them more positively than each of the two families that harmed them. On each row, different subscripts indicate a significant difference, tested as contrasts in the ANOVA. 
17 RUNNING HEAD: The Independent Effect of CO-OCCURRENCE

$84 \%$ of the participants in Experiment $1,67 \%$ of the participants in Experiment 2, and $71 \%$ of the participants in Experiment 3 had accurate memory regarding the action each family performed during the game. To make sure that the results are not affected by people who misunderstood instructions or did not pay attention to the relational information, we repeated the same analyses with two subsamples: One subsample included only participants who had perfect memory for the action each family performed during the game. The second subsample included participants who had perfect memory and also rated each of the two families that helped them more positively than the two families that harmed them. This latter group showed excellent comprehension of the relational information.

The results with those subsamples are presented in Table 1. We report here only the most stringent test: the 2 (co-occurring valence) x 2 (target's role) ANOVA with only participants who had accurate memory and displayed rating that reflected the true valence of the targets (i.e., higher ratings of each helper over each harmer). As expected (and determined by the selection rule of this subsample), the ANOVA found a main effect of target's role in all three experiments: Experiment 1: $F(1,32)=$ 144.76, $p<.001,{ }_{\eta_{p}}{ }^{2}=.81$; Experiment $2: F(1,20)=74.47, p<.001,{ }_{\eta_{p}}{ }^{2}=.78$;

Experiment 3: $F(1,30)=263.49, p<.001,{ }_{\eta_{p}}{ }^{2}=.89$. Most importantly, the effect of co-occurring valence was consistent and usually statistically reliable in all three experiments: Experiment 1: $F(1,32)=7.94, p=.008,{ }_{\eta_{p}}{ }^{2}=.19,90 \%$ CI $[.03, .37]$; Experiment 2: $F(1,20)=3.60, p=.07,{ }_{\eta_{p}}{ }^{2}=.15,90 \%$ CI $[.00, .36]$; Experiment 3: $F(1,30)=22.69, p<.001, \eta_{p}^{2}=.43,90 \%$ CI $[.19, .58] ;$ That main effect reflected more liking of the targets that co-occurred with positive USs $(M s=3.82,3.55,3.71$, $S D s=0.46,0.27,0.54$, in Experiments 1, 2 and 3, respectively) than targets that co- 
18 RUNNING HEAD: The Independent Effect of CO-OCCURRENCE

occurred with negative USs $(M s=3.53,3.36,3.24, S D s=0.48,0.32,0.51), d s=0.61$, 0.64, 0.89, in Experiments 1-3, respectively. These effects were larger in the subsamples than in the entire samples, indicating that better comprehension did not reduce the co-occurrence effect.

\section{Discussion}

Experiments 1-3 provide more evidence that relational qualifiers moderate the effect of CS-US co-occurrence on evaluation (Fiedler \& Unkelbach, 2011; Förderer \& Unkelbach, 2012; Walther, Langer, Weil, \& Komischke, 2011; Zanon, De Houwer, Gast, \& Smith, 2014). Importantly, these results are compatible with the hypothesis that co-occurrence has an effect on evaluation above and beyond the effect of relational information. To understand our interpretation of the results better, note that the main effect of co-occurrence means that in Experiment 1, for example, the preference for targets that ended negative events over targets that ended positive events was smaller than the preference for targets that started positive events over targets that started negative events. We propose that the reason for these results is an assimilative effect of co-occurrence: the relational information for targets ending positive stimuli pushed the evaluation to the negative pole whereas the co-occurrence pushed the evaluation to the positive pole. The result of those conflicting forces is an attenuated disliking of the target that ended positive stimuli and an attenuated liking of the target that ended negative stimuli (see Table 1). That leads to a reduced potency of the relation end in inducing attitudes, in comparison to the relation start.

However, although the results are compatible with co-occurrence account, the results might reflect a difference in the potency of relations in inducing attitudes rather than an effect of co-occurrence. That is, the reduced potency of the relations end, take, and prevent in comparison to the relations start, give, and allow is due to 
19 RUNNING HEAD: The Independent Effect of CO-OCCURRENCE

reasons other than co-occurrence with affective stimuli. For example, the relations take, prevent and end might be conceived as diminishing the effect of affective stimuli, whereas give, allow, and start facilitate the effect of affective stimuli. Perhaps relations that diminish are less potent in attitude induction than relations that facilitate because people consider facilitation as stronger evaluative evidence than diminishing. Another possibility is that the relations give, allow and start seem active actions while the relations take, prevent and end seem passive actions. Perhaps active actions are more potent in inducing evaluation than passive actions (Paxton \& Greene, 2010).

These alternative accounts are speculative. Still, in Experiments 4 and 5 we bypassed these alternative accounts by manipulating the focus on the co-occurrence. If focusing participants on co-occurrence during the learning would increase the assimilative effect of the US despite perfect comprehension of the relational information, that effect could be attributed only to the co-occurrence with the US, and not to differences in the potency of the relations.

\section{Experiment 4}

We adapted a previous procedure that used the relations characteristic and uncharacteristic (Peters \& Gawronski, 2011). Participants observed men who cooccurred with positive or negative behaviors and received an indication whether the behaviors were characteristic or uncharacteristic of each man. The behaviors were not attributed to the men, only provided as examples for behaviors that are either characteristic or uncharacteristic of each man. One man occurred with positive behaviors that characterized him, and one occurred with characteristic negative behaviors. The other two men co-occurred with behaviors presented as uncharacteristic of them: one with positive behaviors and one with negative behaviors. The men who were presented with uncharacteristic behaviors co-occurred 
20 RUNNING HEAD: The Independent Effect of CO-OCCURRENCE

with stimuli of one valence but their relation with those stimuli indicated they have the opposite valence.

We tested whether the assimilative effect of the US would be stronger when we focus participants on the stimuli with which the men co-occurred than when participants focus on the evaluation of the men (the focus manipulation was adapted from Moran, Bar-Anan \& Nosek, 2015). The focus manipulation does not seem relevant to accounts that attribute the previous effects to differences in the potency of some relational qualifiers versus others. Therefore, if focus on the co-occurring stimuli would increase the assimilative effect, it would provide more direct evidence that co-occurrence has an assimilative effect that is not cancelled by relational information that the co-occurring stimuli are of opposite valence.

\section{Method}

Participants. 275 participants volunteered to participate in this study on the internet at the Project Implicit research website $\left(60 \%\right.$ women, $M_{\text {age }}=30.35, S D_{\text {age }}=$ 12.84). Although we do not remember our sample size plans, the decision to stop the experiment did not depend on the results. ${ }^{6}$

\section{Materials and procedure.}

Stimuli. The four targets were pictures of young adult white males (Minear \& Park, 2004; pre-tested by Bar-Anan \& Amzaleg-David, 2014). We named them Chris, James, Michael and David. There were 24 positive behaviors (e.g., Took his younger brother to a movie) and 24 negative behaviors (e.g., Told a lie about his friend) for the learning phase.

\footnotetext{
${ }^{6}$ The experiment was removed from the website after a week because its completion rate $(53 \%, 275 / 516)$ was lower than the typical study in Project Implicit (around 65\% completion rate).
} 
21 RUNNING HEAD: The Independent Effect of CO-OCCURRENCE

Learning. Participants were instructed to imagine that they are about to start a new job and want to learn about four co-workers. Each trial in the task presented a man (CS) and a behavior (US). Participants had to indicate with a response key whether the behavior was characteristic or uncharacteristic of the man, and then feedback appeared for $1000 \mathrm{~ms}$ indicating correct or incorrect response. After the basic instructions for the task, participants in the focus on co-occurrence condition read the instructions "Please try to remember which men always appear with positive behaviors (regardless of whether the behaviors are characteristic or uncharacteristic of the man) and which men always appear with negative behaviors (regardless of whether the behaviors are characteristic or uncharacteristic of the man)." In the focus on relational information condition the additional instructions were "Please form an impression of the four men, based on the behaviors that characterize and do not characterize them." There were no additional instructions in the control condition.

The learning task had three blocks, each with four trials for each man $(3 * 16$ trials total). We assigned the four men to four roles following these rules: Chris and Michael always co-occurred with behaviors with the same valence (e.g., positive), and James and David always co-occurred with behaviors of the opposite valence. David and Michael always appeared with behaviors that were all characteristic or all uncharacteristic (the opposite condition from James and Chris).

After each block of the characteristic/uncharacteristic task, participants in the focus on relational information condition completed a questions block, in which they saw each man separately (i.e., four trials) and had to indicate whether the man was positive or negative. Participants in the co-occurrence focus condition also completed a question block, but had to indicate whether each man appeared with positive or negative behaviors. There were no questions blocks in the control condition. 
Measures. After the learning task, participants completed measures of automatic evaluation and deliberate evaluation in random order, and then the memory measure. Because automatic evaluation is not the focus of the present investigation, we report these results in an online supplement (https://osf.io/k96e2/).

Deliberate Evaluation. Participants reported on a 7-point scale how much they liked each man (1=dislike extremely, $7=$ like extremely), and how friendly and trustfully each men is ( $1=$ not at all, $7=$ very much). The questions were presented in a random order. We averaged the ratings for each man $(\alpha>.89)$.

Memory. In four separate questions, we asked participants to indicate what we told them about each of the four men. The response options were: Positive behaviors were characteristic of him, Positive behaviors were uncharacteristic of him, Negative behaviors were characteristic of him, and Negative behaviors were uncharacteristic of him.

Design. The design was 3 (focus: on inference from relational information, on co-occurrence, no-focus; between participants) X 2 (co-occurring [US] valence: positive, negative; within participants) X 2 (target's [CS] role: positive, negative; within participants) X 2 (measures order: deliberate first, automatic first; between participants).

\section{Results}

The upper part of Table 2 presents the evaluation scores for each target type, for each focus condition. We submitted the evaluation scores to a 3 (focus) x 2 (US valence) $\mathrm{x} 2$ (target's role) $\mathrm{x} 2$ (measures order) ANOVA. A strong main effect of target's role, $F(1,269)=976.89, p<.001, \eta_{p}{ }^{2}=.78,90 \%$ CI $[.74, .81]$, reflected more liking of positive men $(M=5.71, S D=0.97)$, than negative men $(M=2.43, S D=$ 
1.02). Replicating the results of Experiments 1-3 with another pair of relations, the ANOVA found a main effect of US valence, $F(1,269)=100.21, p<.001, \eta_{p}{ }^{2}=.27$, $90 \%$ CI $[.19, .33]$, reflecting more liking of men who co-occurred with positive behaviors $(M=4.43, S D=0.75)$ than of men who co-occurred with negative behaviors $(M=3.71, S D=0.81)$. The effect of US valence was further moderated by target's role, $F(1,269)=4.37, p=.037,{ }_{\eta_{p}}{ }^{2}=.03,90 \% \mathrm{CI}[.00, .04]$. That interaction revealed a stronger effect of co-occurring valence when target's role was positive, $F(1,274)=88.54, p<.001,{ }_{\eta_{p}}{ }^{2}=.24$, than when target's role was negative, $F(1,274)$ $=46.94, p<.001, \eta_{p}^{2}=.14$.

Most importantly, focus moderated the effect of US valence, $F(2,269)=5.51$, $p=.004, \eta_{p}{ }^{2}=.03,90 \%$ CI $[.007, .07]$. As expected, the interaction reflected stronger co-occurrence effect when we focused participants on the co-occurrence, $F(1,89)=$ $50.47, p<.001, \eta_{p}{ }^{2}=.36,90 \% \mathrm{CI}[.23, .46]$, than when participants were asked to form impression of the men, $F(1,95)=22.28, p<.001, \eta_{p}{ }^{2}=.18,90 \%$ CI $[.08, .29]$, or when participants received no focus instructions, in the control condition, $F(1,88)$ $=29.80, p<.001, \eta_{p}{ }^{2}=.25,90 \%$ CI $[.12, .36]$. Notice that in all three focus conditions, co-occurrence had a strong effect on evaluation above and beyond the effect of relational information. However, this effect became stronger when participants focused on the co-occurrence (Table 2). ${ }^{7}$

We next examined whether the reason for the predicted moderation effect was that participants who memorized the co-occurrence were so focused on co-occurrence that they did not learn the relational information and did not notice which man was

7 There was also a significant four-way interaction between focus, US valence, target's role and measures order, $F(2,269)=3.26, p=.039, \eta_{p}{ }^{2}=.02$, which was not important theoretically and therefore was not analyzed further. 
positive and which was negative. Contradicting that possibility, the rate of participants with accurate memory regarding all target men was only slightly lower in the co-occurrence focus (65\%) than in the relational information focus $(73 \%)$ condition, $X^{2}(1, N=186)=1.55, p=.212$. The accuracy rate in the co-occurrence focus condition also did not differ from the accuracy rate in the control condition $(60 \%), X^{2}(1, N=179)=0.45, p=.500$, which showed results more similar to the preference shown in the relational information focus condition than in the cooccurrence focus condition.

Like in the previous experiments, we repeated the analyses also with a subsample of participants who had perfect memory for the valence of each man (Table 2). We found the same results as with the entire sample. A strong main effect of target's role, $F(1,175)=1139.90, p<.001, \eta_{p}{ }^{2}=.86,90 \%$ CI $[.83, .88]$, reflected more liking of positive men $(M=5.97, S D=0.83)$, than negative men $(M=2.21, S D$ $=0.90)$. A main effect of US valence, $F(1,175)=60.28, p<.001, \eta_{p}{ }^{2}=.25,90 \% \mathrm{CI}$ $[.16, .33]$, reflected more liking of men who co-occurred with positive behaviors $(M=$ 4.37, $S D=0.64)$ than of men who co-occurred with negative behaviors $(M=3.82, S D$ $=0.65)$. The interaction between US valence and target's role was no longer significant $\left(\eta_{p}^{2}=.02\right)$.

Importantly, even with this accurate subsample, focus had an effect of the same size as in the whole sample, although the smaller sample reduced its statistical reliability, $F(2,175)=2.58, p=.079, \eta_{p}{ }^{2}=.03,90 \% \mathrm{CI}[.00, .07]$. As expected, the interaction reflected stronger co-occurrence effect when participants focused on the co-occurrence, $F(1,57)=35.40, p<.001, \eta_{p}{ }^{2}=.38,90 \%$ CI $[.21, .50]$, than when we focused them on the inference from the relational information, $F(1,69)=13.17, p<$ $.001, \eta_{p}{ }^{2}=.16,90 \% \mathrm{CI}[.04, .28]$, or when they received no focus instructions in the 
25 RUNNING HEAD: The Independent Effect of CO-OCCURRENCE

control condition, $F(1,52)=18.94, p<.001, \eta_{p}{ }^{2}=.26,90 \% \mathrm{CI}[.10, .40]$. In all three focus conditions, co-occurrence had a strong effect on evaluation above and beyond the effect of relational information, and this effect became stronger when participants focused on the co-occurrence.

Table 2

Experiment 4: Evaluation as a function of co-occurring valence and target's role in each focus condition

\begin{tabular}{|c|c|c|c|c|c|c|c|}
\hline $\begin{array}{c}\text { Target's role } \\
\text { Co-occurring } \\
\text { valence }\end{array}$ & & $\begin{array}{l}\text { Positive } \\
\text { Positive }\end{array}$ & $\begin{array}{l}\text { Positive } \\
\text { Negative }\end{array}$ & $\begin{array}{l}\text { Negative } \\
\text { Positive }\end{array}$ & $\begin{array}{l}\text { Negative } \\
\text { Negative }\end{array}$ & \multicolumn{2}{|c|}{$\begin{array}{c}\text { Effect of co-occurring } \\
\text { valence }\end{array}$} \\
\hline $\begin{array}{l}\text { All } \\
\text { participants }\end{array}$ & $\mathbf{N}$ & & & & & $\begin{array}{l}\text { Positive } \\
\text { stimuli }\end{array}$ & $\begin{array}{c}\text { Negative } \\
\text { stimuli }\end{array}$ \\
\hline $\begin{array}{l}\text { Focus on } \\
\text { relational } \\
\text { information }\end{array}$ & 96 & $6.08_{\mathrm{a}}(1.18)$ & $5.43_{\mathrm{b}}(1.31)$ & $2.55_{\mathrm{c}}(1.32)$ & $2.10_{\mathrm{d}}(1.24)$ & $4.31(0.74)$ & $3.76(0.74)$ \\
\hline Control & 89 & $6.11_{\mathrm{a}}(0.98)$ & $5.54_{b}(1.09)$ & $2.77_{\mathrm{c}}(1.28)$ & $2.23_{\mathrm{d}}(1.33)$ & $4.44(0.66)$ & $3.88(0.71)$ \\
\hline $\begin{array}{l}\text { Focus on co- } \\
\text { occurrence }\end{array}$ & 90 & $6.17_{\mathrm{a}}(1.05)$ & $4.93_{\mathrm{b}}(1.48)$ & $2.92_{\mathrm{c}}(1.31)$ & $2.04_{d}(1.08)$ & $4.54(0.82)$ & $3.48(0.92)$ \\
\hline Only participa & IS V & h perfect me & ory & & & & \\
\hline $\begin{array}{l}\text { Focus on } \\
\text { relational } \\
\text { information }\end{array}$ & 70 & $6.27_{\mathrm{a}}(1.02)$ & $5.77_{b}(1.15)$ & $2.28_{\mathrm{c}}(1.21)$ & $1.95_{\mathrm{d}}(1.04)$ & $4.27(0.68)$ & $3.86(0.66)$ \\
\hline Control & 53 & $6.37 \mathrm{a}(0.73)$ & $5.86_{\mathrm{b}}(0.88)$ & $2.36_{c}(1.11)$ & $1.95_{\mathrm{d}}(1.13)$ & $4.36(0.54)$ & $3.90(0.61)$ \\
\hline $\begin{array}{l}\text { Focus on co- } \\
\text { occurrence }\end{array}$ & 58 & $6.20_{a}(0.93)$ & $5.38_{\mathrm{b}}(1.11)$ & $2.78_{\mathrm{c}}(1.11)$ & $2.01_{d}(0.93)$ & $4.49(0.65)$ & $3.69(0.67)$ \\
\hline
\end{tabular}

Notes. Target's role is the target's evaluation inferred from the relational information.

On each row, different subscripts indicate a significant difference, tested as contrasts in the ANOVA. 
26 RUNNING HEAD: The Independent Effect of CO-OCCURRENCE

\section{Discussion}

The results of the Experiment 4 support the hypothesis that co-occurrence has an effect on evaluation above and beyond the effect of relational information. When participants focused on the valence of the US, the assimilative effect of the US was stronger. The focus on co-occurrence did not reduce the comprehension of the relational information, but it still increased the assimilative effect of the US, suggesting that co-occurrence with affective stimuli influences evaluation even when people fully understand that the relational information indicates that the co-occurring stimuli are of opposite valence.

\section{Experiment 5}

Experiment 5 was a conceptual replication of Experiment 4, conducted in the lab rather than over the Internet, and used a different learning paradigm and different relations. We adapted the learning procedure from Moran and Bar-Anan (2013). Participants observed target characters that started or ended pleasant or unpleasant sounds. We tested whether the assimilative effect of the US (the sound that cooccurred with each target) would be stronger when participants focused on the stimuli with which the characters co-occurred than when participants focused on the evaluation of the characters' behavior. As in Experiment 4, if focus on the cooccurring stimuli would have an assimilative effect on evaluation despite comprehending what evaluation is indicated by the relational qualifiers, it would support the hypothesis that the assimilative effect of co-occurrence is not completely cancelled by contradicting relational information.

\section{Method}

Participants. 73 student participants in an Israeli university completed the study in cubicles $\left(82 \%\right.$ women, $\left.M_{\text {age }}=22.92, S D_{\text {age }}=1.28\right)$. We planned to run 24 
27 RUNNING HEAD: The Independent Effect of CO-OCCURRENCE

participants per condition, based on the effect sizes found with a similar study in our lab that measured automatic evaluation (Moran, Bar-Anan, \& Nosek, 2015). We inadvertently collected data from one participant more than planned.

\section{Materials and Procedure}

Materials. Target stimuli were identical to the targets used in Experiments 13. The affective stimuli during learning were a relaxing musical melody and an unpleasant human scream (Moran \& Bar-Anan, 2013).

Learning procedure. Instructions informed participants that they would listen a few times to two different sound segments and that four families would each have one constant role throughout the task: starting one of the segments or ending one of the segments. We counterbalanced between participants which family performed each of the four roles.

We randomly assigned participants to one of three focus conditions. In the focus on relational information condition, we instructed participants to learn whether each family is good or bad for them. In the co-occurrence focus condition we instructed participants to learn to which sound each family was related. There were no specific instructions in the control condition.

The learning included 12 music (positive sound) trials and 12 scream (negative sound) trials, separated by a soft ticking sound that played for 10-15 seconds. Each trial in the task began with a presentation of the "starting" character, appearing in silence for 500ms. Next, the auditory stimulus began, playing for a randomly determined duration of 10-30 seconds. The "starting" character remained on the screen for the first two seconds of the playback. Then the screen turned blank until the "ending" character appeared for the last two seconds of the auditory stimulus' playback and remained on the screen for another 
28 RUNNING HEAD: The Independent Effect of CO-OCCURRENCE

$500 \mathrm{~ms}$ of silence. When the screen turned blank, the ticking sound commenced until the next trial started.

The 24 trials were divided to four blocks, each with three trials for each sound. After each block, participants completed a questions block, in which they answered one question about each of the four families. In the focus on relational information condition, the question was "did this family help you or harm you?", and participants could choose "this family helped me" or "this family harmed me". In the co-occurrence focus condition, we asked "was this family related to positive or negative sound?" and participants could respond "this family was related to positive sound" or "this family was related to negative sound." Feedback at the end of the trial indicated whether the answer was correct. There were no questions blocks in the control condition.

Evaluation. After the learning task, participants reported on a 9-point scale how much they liked each character in a total of 16 questions - rating four characters from each family ( 1 = dislike strongly, $9=$ like strongly). We averaged the ratings for each family $(\alpha>.94)$.

Memory. After the evaluation, participants indicated the action each family performed during the game (in four questions: one family at a time). The response options listed the four possible actions, of which the participants chose one.

Design. The design was 3 (focus: on inference from relational information, on co-occurrence, no focus; between participants) X 2 (co-occurring [US] valence: positive, negative; within participants) X 2 (target's [CS] role: positive, negative; within participants). 
29 RUNNING HEAD: The Independent Effect of CO-OCCURRENCE

\section{Results}

Table 3 presents the evaluation scores for each target type, for each focus condition. We submitted the evaluation scores to a 3 (focus) $\times 2$ (US valence) $\times 2$ (target's role) ANOVA. A main effect of target's role, $F(1,70)=186.10, p<.001, \eta_{p}{ }^{2}$ $=.72,90 \% \mathrm{CI}[.63, .78]$, reflected more liking of targets that helped participants $(M=$ $6.71, S D=1.57)$, than targets that harmed participants $(M=3.41, S D=1.38)$. The target's role effect was moderated by focus condition, $F(2,70)=16.59, p<.001, \eta_{p}{ }^{2}=$ $.32,90 \% \mathrm{CI}[.16, .43]$, reflecting a stronger effect of target's role among participants who focused on the relational information, $F(1,23)=137.61, p<.001, \eta_{p}{ }^{2}=.85,90 \%$ CI $[.73, .89]$, than among participants in the control condition, $F(1,23)=56.41, p<$ $.001, \eta_{p}^{2}=.71,90 \%$ CI $[.50, .79]$, or participants who focused on co-occurrence, $F(1$, 24) $=16.68, p<.001, \eta_{p}{ }^{2}=.41,90 \%$ CI $[.14, .57]$.

Replicating the evidence that co-occurrence influence evaluation independently of the effect of other relational information, the ANOVA showed a strong main effect of US valence, $F(1,70)=139.03, p<.001, \eta_{p}^{2}=.66,90 \%$ CI $[.55$, .73], reflecting more liking of targets who co-occurred with positive sounds $(M=$ $6.15, S D=0.97)$ than of targets who co-occurred with negative sounds $(M=3.97, S D$ $=1.28)$.

The most important question in the present experiment was whether focus on co-occurrence would increase the assimilative effect of the US. We found evidence in support of that prediction, $F(2,70)=3.22, p=.045, \eta_{p}{ }^{2}=.08,90 \%$ CI $[.008, .18]$. As expected, the interaction reflected stronger co-occurrence effect when participants focused on co-occurrence, $F(1,24)=64.99, p<.001, \eta_{p}{ }^{2}=.73,90 \%$ CI $[.53, .80]$, than when they focused on the relational information, $F(1,23)=34.03, p<.001, \eta_{p}{ }^{2}=$ $.59,90 \%$ CI $[.39, .71]$, or in the control condition, $F(1,23)=42.92, p<.001, \eta_{p}{ }^{2}=$ 
30 RUNNING HEAD: The Independent Effect of CO-OCCURRENCE

$.65,90 \% \mathrm{CI}[.41, .75]$. Interestingly, the effect of the linked valence was so strong in the co-occurrence focus condition that the family that ended pleasant music was rated more positively than the family that ended unpleasant screams, although this tendency was not statistically reliable, $F(1,24)=3.82, p=.062, \eta_{p}{ }^{2}=.13,90 \%$ CI $[.00, .33] .^{8}$

We next examined whether the reason for the predicted moderation effect was that participants who memorized the co-occurrence were so focused on co-occurrence that they did not learn the relational information and did not notice which target was positive and which was negative. Contradicting that possibility, all of the participants in the co-occurrence focus condition and the focus on relational information condition had perfect memory regarding all targets.

Table 3

Experiment 5: Evaluation as a function of co-occurring valence and target's role in each focus condition

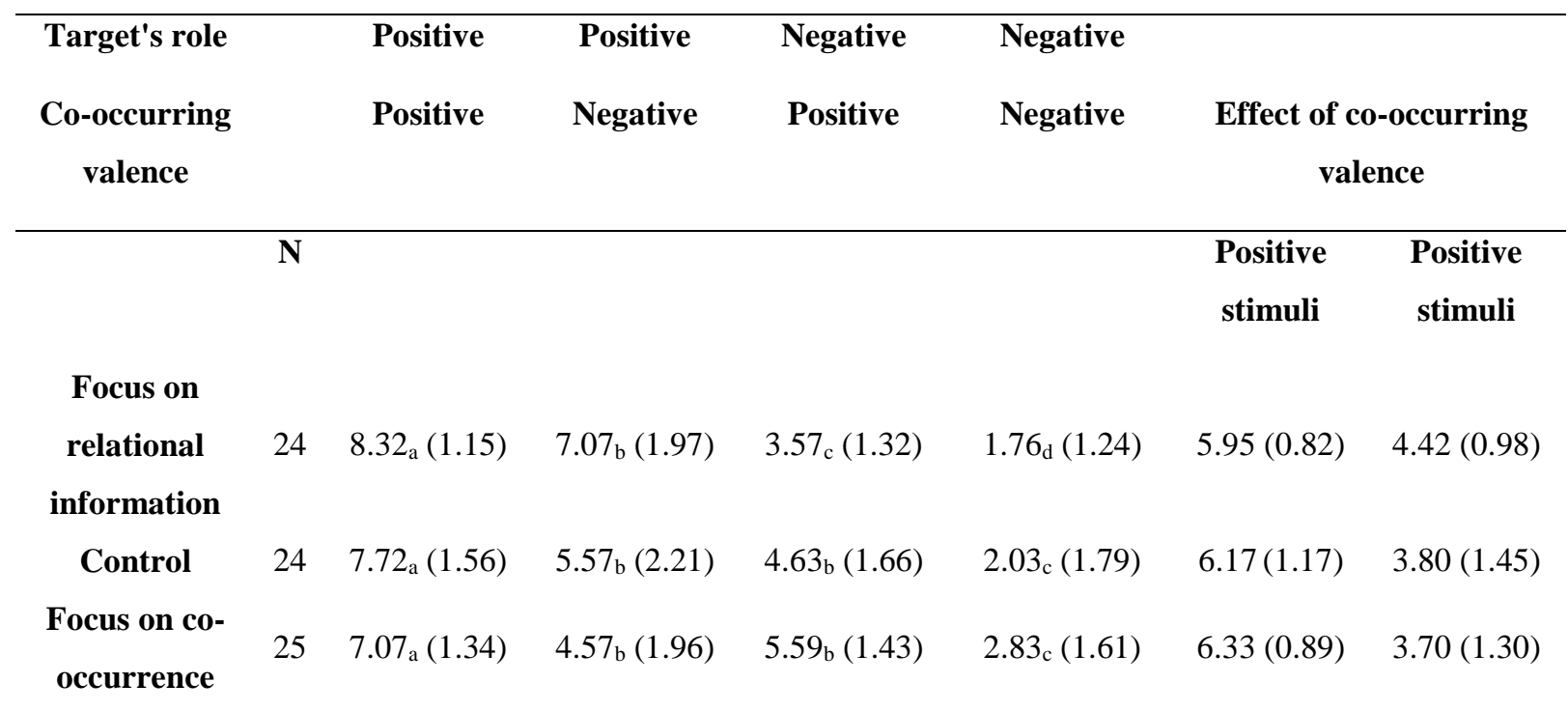

Notes. On each row, different subscripts indicate a significant difference, tested as contrasts in the ANOVA.

${ }^{8}$ Increasing confidence in the reliability of these results, we found a similar effect $\left(\eta_{p}{ }^{2}\right.$ $=.07, p=.023$ ) in a previous experiment in which deliberate evaluation was used only for exploratory reasons (see supplement materials of Moran et al., 2015). 
31 RUNNING HEAD: The Independent Effect of CO-OCCURRENCE

\section{Discussion}

Experiment 5 replicated the results of Experiment 4, with even more conclusive results. When participants focused during learning on the co-occurring stimuli, the assimilative effect of the US was stronger. The assimilative effect of the US was so strong in that condition that participants rated more favorably the family that ended pleasant music than the family that ended unpleasant scream. Together, the results of Experiments 4-5 provide more support for the assumption that cooccurrence has an assimilative effect on evaluation even when people comprehend the relational information that indicates that the co-occurring stimuli are of opposite valence. $^{9}$

\section{General Discussion}

In five experiments, we found evidence consistent with the hypothesis that cooccurrence has an independent assimilative effect on evaluation above and beyond the effect of relational qualifiers. Five experiments provided support for this hypothesis, using various relations, different sets of stimuli, and a number of checks against alternative accounts that could explain prior results (Förderer \& Unkelbach, 2012; Gawronski et al., 2005; Moran \& Bar-Anan, 2013). We measured comprehension and found that co-occurrence has an assimilative effect on evaluation even when people show perfect comprehension of the relational information. In the most stringent comprehension test we included only participants who reported preference for the target that co-occurred with negative stimuli over the target that co-occurred with positive stimuli when the relational information indicated that the stimuli that cooccurred were of opposite valence. Even in that restrictive subsample, co-occurrence

\footnotetext{
${ }^{9}$ We report another conceptual replication that found similar results (a stronger assimilative effect of co-occurrence when participants focused on co-occurrence) in an online supplement (https://osf.io/r42eb/).
} 
still had an assimilative effect on evaluation, attenuating the liking and disliking induced toward those targets. These results discount alternative explanations that some participants did not comprehend the relational information.

Experiments 4-5 overcame other alternative accounts. According to the cooccurrence account that we propose in the present research, when people observe relations that indicate that a CS has the opposite valence of the co-occurring US their evaluation of the CS is sensitive to two conflicting forces. One force is the relational information that pushes the evaluation of the CS to valence opposite of the US, whereas the other force is the co-occurrence that pushes the CS evaluation to the same valence as the US. When the relations indicate that the CS and the US are similar in valence, the two forces push to the same direction, thus inducing more extreme attitudes than relations that indicate CS-US opposition. According to the alternative accounts, reasons unrelated to the co-occurrence attenuate the extremity of the evaluation when the relation indicates CS-US opposition. For example, perhaps relations that diminish the effect of a US (e.g., end, prevent, take away) are considered weaker evidence about the evaluation of the CS than relations that facilitate the effect of the US (e.g., start, allow, give). To overcome any alternative account of that sort, in Experiment 4 and 5 we manipulated the focus on the cooccurrence. If focus on co-occurrence increases the assimilative effect of the US, that increase could not be attributed to any inherent weakness of relations that indicate CS-US opposition other than the co-occurrence itself. In both experiments-each with different relations and a different learning procedure - we found that focus on cooccurrence increased the assimilative effect of the US on the CS evaluation. Although the alternative accounts might still apply to all the previous results and the results of Experiments 1-3, these alternative accounts do not seem relevant to the results of 
33 RUNNING HEAD: The Independent Effect of CO-OCCURRENCE

Experiments 4-5. Therefore, these results are more support for the assumption that cooccurrence with affective stimuli has an assimilative effect on evaluation even when relational information indicates that the co-occurring US is of valence opposite to the valence of the $\mathrm{CS}$.

\section{Implications for the Advance of EC Research}

Much is known about the procedural conditions in EC under which cooccurrence between stimuli results in an assimilative effect (for reviews, see De Houwer, Thomas, \& Baeyens, 2001; Hofmann, et. al., 2010; Walther, Weil, \& Langer, 2011). Most studies deliberately eliminated any explicit information other than co-occurrence about the relation between the stimuli. Yet, in real life, relational information is often available. Even when relational information is not available, nothing stops humans from assuming or inferring CS-US relations. Even in standard EC procedures, it is possible that people assume specific relations between the cooccurring CS and US.

Existing EC research that included manipulations of relational information in addition to co-occurrence mostly focused on the fact that people can infer that the CS valence is the opposite of the US valence if the relational information suggests that the CS and the US are opposite (Fiedler \& Unkelbach, 2011; Förderer \& Unkelbach, 2012; Zanon, De Houwer, Gast, \& Smith, 2014). Such results show that people can understand relational information and take it into account upon judgment. Indeed, cooccurrence is not the only factor that influences evaluation. Other factors, such as mere exposure (Zajonc, 1968), and specific information about the target stimulus (e.g., that target person's race) also influence evaluation. Often, those factors have stronger influence on evaluation than the effect of mere co-occurrence with affective stimuli, as does providing relational information. 
We added to this literature by testing whether relational information cancels the assimilative effect of co-occurrence with affective stimuli. If relational information easily overrides the effect of co-occurrence on evaluation, then mere cooccurrence is of little relevance to most real life evaluative learning episodes. Further, if the relational information determines evaluation then perhaps most previous effects observed in EC research were the result of people's inferences about the relation. Perhaps most EC procedures elicited an implicit or explicit assumption that cooccurring stimuli are similar. Our findings suggest, however, that co-occurrence is influential independently of other relational information, and investigating the rules that govern its assimilative effect on evaluation is valuable.

Future research should investigate directly if the many findings regarding the effect of co-occurrence on evaluation operate similarly when more information about the CS-US relations is available. For example, the CS holds the US valence even after the CS is presented alone multiple times (i.e., EC resists extinction; Baeyens et al., 1988; Díaz, Ruiz, \& Baeyens, 2005; Gawronski, Gast, \& De Houwer, 2015). If people are told that a CS is the opposite of a US, would the independent assimilative effect of presenting CS-US co-occurrences persists even after presenting the CS alone several times (i.e., extinction)? Also, previous research found that a post-pairing flip in the valence of the US flips the effect of co-occurrence on evaluation (Walther et al., 2009). The addition of explicitly relational information opens new research questions: if Batman fought against a criminal who was later revealed to be an undercover policewoman, Batman's knowledge on the person's true identity is crucial for evaluating Batman. However, Batman's knowledge might have no influence on the effect of co-occurrence, showing a discrepancy between the factors that moderate these two effects, and providing more clues about the processes that underlie them. 
Similar questions can be investigated regarding other phenomena previously investigated about EC, such as the effect of variation in the number of CS-US pairings, overshadowing, blocking, pairing with multiple versus one US, and variations in the CS-US density. Do those factors operate the same when people have explicit knowledge about how the CS and the US relate to each other (beyond cooccurrence)?

An independent assimilative effect of CS-US co-occurrence is compatible with the basic assumptions of associative accounts for EC. These accounts assume that observing co-occurrence automatically forms a mental representation that includes the CS and the US valence. Upon CS evaluation, the activation of that representation contributes to the CS evaluation, pushing it toward the US valence (Gawronski \& Bodenhausen, 2006; Hofmann, et. al., 2010). An associative account for EC does not have to reject the assumption that in parallel to the associative processes, propositional processes encode the relational information and allow inference about the CS valence. Associative accounts for EC argue that associative processes underlie the effect of CS-US co-occurrence on CS evaluation, not the effects of any information on evaluation.

A propositional model can account for our results by assuming that CS-US cooccurrence is stored in memory as a CS-US relation (e.g., the proposition the CS and US co-occur), and that relation has an assimilative effect on CS evaluation. Propositional models would need to explain why propositions formed by cooccurrence have an assimilative effect on CS evaluation. Is it a logical inference specific to co-occurrence? Does that inference involve certain assumptions (e.g., the assumption that people who end unpleasant events are somewhat attracted to unpleasant events)? What conditions would alter that inference? What other relations 
36 RUNNING HEAD: The Independent Effect of CO-OCCURRENCE

would lead to similar versus opposite effects? Thus, the present research could serve as a springboard for developing propositional models that could have better contribution for research on evaluative learning.

\section{Future Developments in EC Research}

Integrating relational information other than co-occurrence into experimental procedures that repeatedly presents CS-US co-occurrences is an important step toward a better integration of research under the EC tradition into the broader field of impression formation research. Impression formation is a rich research tradition that studies how people form impressions of other people. Whereas EC studies have mostly focused on the effect of co-occurrence on evaluation, impression formation studies have covered many other forms of information. Although both EC research and impression formation research study factors that influence evaluation, they often operate without attention to findings and theories from the other line of research. We believe that a better integration of these two fields will make a valuable contribution.

Early impression formation research mainly studied how perceivers draw inferences about other people from partial information (implicit personality theory; e.g., Cantor \& Mischel, 1977; Wishner, 1960), and how perceivers combine different kinds of information to produce an overall impression (information integration; e.g., Anderson, 1965; Rosenkrantz, \& Crockett, 1965). Over the years, impression formation studies addressed a wide range of questions such as what factors influence attention during impression formation (e.g., Mayo \& Crockett, 1964), how motivation and mood affect impression formation (e.g., Forgas \& Bower, 1987; Neuberg \& Fiske, 1987), what factors bias impression formation (e.g., Skowronski \& Carlston, 1989), how category accessibility affects the influence of ambiguous description on evaluation (e.g., Higgins, Rholes, \& Jones, 1977), the effects of processing goals (e.g., 
37 RUNNING HEAD: The Independent Effect of CO-OCCURRENCE

Chartrand, \& Bargh, 1996), the effects of prior knowledge (e.g., Cohen, 1981), effects of fluency (e.g., Sansom-Daly \& Forgas, 2010), and many more. The tradition of studying impression formation is also closely tied to research on persuasion (e.g., Hovland, Janis, \& Kelly, 1953; Petty \& Cacioppo, 1986), a line of research that focused on changes in opinions (whether people support or oppose certain beliefs, ideologies, and arguments), and has flourished with many empirical investigations and theoretical models.

Impression formation and persuasion research subsumes a variety of theories about the formation and expression of evaluative behavior. For instance, the Information Integration theory (Anderson, 1981), the Expectancy-value model of attitudes (Fishbein \& Ajzen, 1975), the Elaboration Likelihood Model (ELM; Petty \& Cacioppo, 1986), the Motivation and Opportunity as Determinants of Evaluation (MODE) model (Fazio, 2007), the Associative Propositional Evaluation (APE) model (Gawronski \& Bodenhausen, 2006), the Meta-Cognitive Model (MCM; Petty, Briñol \& DeMarree, 2007), the systems of reasoning approach to attitude change (Rydell et al., 2006), and the iterative-reprocessing model of the neural bases of evaluation (Cunningham \& Zelazo, 2007).

EC research will benefit from taking into account theories and findings from impression formation research. Although EC research deals with evaluative response, general evaluation theories about what influences evaluative response are hardly ever discussed in EC literature. Moreover, impression formation research offers many theoretical, conceptual and empirical insights that could advance EC research. A relatively recent example is the distinction between automatic and deliberate evaluation (Fazio, 2007; Gawronski \& Bodenhausen, 2006; Rydell et al., 2006), which EC research used mainly as a tool for bypassing concerns of experiment 
38 RUNNING HEAD: The Independent Effect of CO-OCCURRENCE

demands, rather than as a tool for understanding the EC effect (for an exception, see Gawronski, Balas, \& Creighton, 2014).

On the other hand, impression formation research has not attempted to integrate EC research much beyond using the basic EC effect to form impressions (often without explicitly calling it EC). Impression formation theories would increase their power and improve their accuracy if they could explain EC findings about blocking (e.g., Lipp, Neumann, \& Mason, 2001), extinction (e.g., Gawronski et al., 2015), contingency memory (e.g., Hütter et al., 2012), order of presentation (e.g., Hammerl \& Grabitz, 1993) counter-conditioning (e.g., Walther et al., 2009), and more. Studies that would investigate the effect of co-occurrence in concert with other evaluative information are likely to utilize methodological and theoretical tools from both research traditions and advance evaluative learning research.

\section{Summary}

We presented evidence that stimulus co-occurrence has an assimilative effect on evaluation, even when other information suggests that the stimuli are of opposite valence. That finding suggests that EC has implications even in complex impression formation circumstances, when co-occurrence is not the only available information. Because most impression formation studies include CS-US co-occurrence, the knowledge gained by EC research about the effect of that co-occurrence is often relevant. Further investigation of the factors that moderate and mediate the assimilative evaluative effect of stimuli co-occurrence could contribute much knowledge about evaluative learning. 
39 RUNNING HEAD: The Independent Effect of CO-OCCURRENCE

\section{References}

Anderson, N. H. (1965). Averaging versus adding as a stimulus-combination rule in impression formation. Journal of Experimental Psychology, 70(4), 394-400.

Anderson, N. H. (1981). Foundations of information integration theory. New York: Academic Press.

Baeyens, F., Crombez, G., Van den Bergh, O., \& Eelen, P. (1988). Once in contact always in contact: Evaluative conditioning is resistant to extinction. Advances in behavior research and therapy, 10(4), 179-199.

Baeyens, F., Eelen, P., \& Crombez, G. (1995). Pavlovian associations are forever: On classical conditioning and extinction. Journal of Psychophysiology 9(2), 127141.

Baeyens, F., Eelen, P., Crombez, G., \& Van den Bergh, O. (1992). Human evaluative conditioning: Acquisition trials, presentation schedule, evaluative style and contingency awareness. Behaviour research and therapy, 30(2), 133-142.

Baeyens, F., Eelen, P., Van den Bergh, O., \& Crombez, G. (1992). The content of learning in human evaluative conditioning: Acquired valence is sensitive to US revaluation. Learning and Motivation, 23(2), 200-224.

Bar-Anan, Y., \& Amzaleg-David, E. (2014). The effect of evaluation on cooccurrence memory judgement. Cognition and Emotion, 28(6), 1030-1046.

Bar-Anan, Y., De Houwer, J., \& Nosek, B. A. (2010). Evaluative conditioning and conscious knowledge of contingencies: A correlational investigation with large samples. The Quarterly Journal of Experimental Psychology, 63(12), 2313-2335.

Cantor, N., \& Mischel, W. (1977). Traits as prototypes: Effects on recognition memory. Journal of Personality and Social Psychology, 35(1), 38-48. 
40 RUNNING HEAD: The Independent Effect of CO-OCCURRENCE

Chartrand, T. L., \& Bargh, J. A. (1996). Automatic activation of impression formation and memorization goals: Nonconscious goal priming reproduces effects of explicit task instructions. Journal of Personality and Social Psychology, 71(3), 464-478.

Cohen, C. E. (1981). Person categories and social perception: Testing some boundaries of the processing effect of prior knowledge. Journal of Personality and Social Psychology, 40(3), 441-452.

Cunningham, W. A., \& Zelazo, P. D. (2007). Attitudes and evaluations: A social cognitive neuroscience perspective. Trends in cognitive sciences, 11(3), 97104.

De Houwer, J. (2007). A conceptual and theoretical analysis of evaluative conditioning. Spanish Journal of Psychology, 10, 230-241.

De Houwer, J., Thomas, S., \& Baeyens, F. (2001). Association learning of Likes and dislikes: A review of 25 years of research on human evaluative conditioning. Psychological Bulletin, 127, 853-869.

Díaz, E., Ruiz, G., \& Baeyens, F. (2005). Resistance to extinction of human evaluative conditioning using a between-subjects design. Cognition and Emotion, 19, 245-268.

Fazio, R. H. (2007). Attitudes as object-evaluation associations of varying strength. Social Cognition, 25, 603-637.

Fiedler, K., \& Unkelbach, C. (2011). Evaluative conditioning depends on higher order encoding processes. Cognition and Emotion, 25(4), 639-656.

Fishbein, M., \& Ajzen, I. (1975). Belief, attitude, intention, and behavior: An introduction to theory and research. Reading, MA: Addison-Wesley. 
41 RUNNING HEAD: The Independent Effect of CO-OCCURRENCE

Förderer, S., \& Unkelbach, C. (2012). Hating the cute kitten or loving the aggressive pit-bull: EC effects depend on CS-US relations. Cognition \& emotion, 26(3), $534-540$.

Forgas, J. P., \& Bower, G. H. (1987). Mood effects on person-perception judgments. Journal of personality and social psychology, 53(1), 53-60.

Gast, A., \& De Houwer, J. (2013). The influence of extinction and counterconditioning instructions on evaluative conditioning effects. Learning and Motivation, 44(4), 312-325.

Gawronski, B., Balas, R., \& Creighton, L. A. (2014). Can the formation of conditioned attitudes be intentionally controlled? Personality and Social Psychology Bulletin, 40, 419- 432.

Gawronski, B., \& Bodenhausen, G. V. (2006). Associative and prepositional processes in evaluation: An integrative review of implicit and explicit attitude change. Psychological Bulletin, 132(5), 692-731.

Gawronski, B., \& Bodenhausen, G. V. (2014). The associative- propositional evaluation model: Operating principles and operating conditions of evaluation. In J. W. Sherman, B. Gawronski, \& Y. Trope (Eds.), Dual-process theories of the social mind (pp. 188 -203). New York, NY: Guilford Press.

Gawronski, B., Gast, A., \& De Houwer, J. (2015). Is evaluative conditioning really resistant to extinction? Evidence for changes in evaluative judgements without changes in evaluative representations. Cognition and Emotion, 29(5), 816-830.

Gawronski, B., \& Walther, E. (2012). What do memory data tell us about the role of contingency awareness in evaluative conditioning?. Journal of Experimental Social Psychology, 48(3), 617-623. 
42 RUNNING HEAD: The Independent Effect of CO-OCCURRENCE

Gawronski, B., Walther, E., \& Blank, H. (2005). Cognitive consistency and the formation of interpersonal attitudes: Cognitive balance affects the encoding of social information. Journal of Experimental Social Psychology, 41(6), 618626.

Hammerl, M., \& Grabitz, H. J. (1993). Human evaluative conditioning: Order of stimulus presentation. Integrative Physiological and Behavioral Science, 28(2), 191-194.

Higgins, E. T., Rholes, W. S., \& Jones, C. R. (1977). Category accessibility and impression formation. Journal of Experimental Social Psychology, 13(2), 141154.

Hofmann, W., De Houwer, J., Perugini, M., Baeyens, F., \& Crombez, G. (2010). Evaluative conditioning in humans: a meta-analysis. Psychological bulletin, 136(3), 390-421.

Hovland, C. I., Janis, I. L., \& Kelley, H. H. (1953). Communication and persuasion: Psychological studies of opinion change. New Haven, CT: Yale University Press.

Hütter, M., Sweldens, S., Stahl, C., Unkelbach, C., \& Klauer, K. C. (2012). Dissociating contingency awareness and conditioned attitudes: evidence of contingency-unaware evaluative conditioning. Journal of Experimental Psychology: General, 141(3), 539-557.

Levey, A. B., \& Martin, I. (1975). Classical conditioning of human 'evaluative' responses. Behaviour Research and Therapy, 4, 205-207.

Lipp, O. V., Neumann, D. L., \& Mason, V. (2001). Stimulus competition in affective and relational learning. Learning and Motivation, 32(3), 306-331. 
43 RUNNING HEAD: The Independent Effect of CO-OCCURRENCE

Martin, I., \& Levey, A. B. (1978). Evaluative conditioning. Advances in Behaviour Research and Therapy, 1, 57-102.

Martin, I., \& Levey, A. B. (1994). The evaluative response: Primitive but necessary. Behaviour Research and Therapy, 32, 301-305.

Mayo, C. W., \& Crockett, W. H. (1964). Cognitive complexity and primacy-recency effects in impression formation. The Journal of Abnormal and Social Psychology, 68(3), 335-338.

Minear, M., \& Park, D. C. (2004). A lifespan database of adult facial stimuli. Behavior Research Methods, Instruments, \& Computers, 36(4), 630-633.

Mitchell, C. J., De Houwer, J., \& Lovibond, P. F. (2009). The propositional nature of human associative learning. Behavioral and Brain Sciences, 32, 183-198.

Moran, T., \& Bar-Anan, Y. (2013). The effect of object-valence relations on automatic evaluation. Cognition \& emotion, 27(4), 743-752.

Moran, T., Bar-Anan, Y., \& Nosek, B. A. (2015). Processing goals moderate the effect of co-occurrence on automatic evaluation. Journal of Experimental Social Psychology, 60, 157-162.

Neuberg, S. L., \& Fiske, S. T. (1987). Motivational influences on impression formation: outcome dependency, accuracy-driven attention, and individuating processes. Journal of personality and social psychology, 53(3), 431-444.

Nosek, B. A. (2005). Moderators of the relationship between implicit and explicit evaluation. Journal of Experimental Psychology: General, 134(4), 565-584.

Paxton, J.M., Greene, J.D., (2010). Moral reasoning: Hints and allegations. Topics in Cognitive Science, 2(3), 511-527. 
Peters, K. R., \& Gawronski, B. (2011). Are We Puppets on a String? Comparing the Impact of Contingency and Validity on Implicit and Explicit Evaluations. Personality and Social Psychology Bulletin, 37(4), 557-569.

Petty, R. E. Briñol, P., \& DeMarree, K. G. (2007). The Meta-Cognitive Model (MCM) of attitudes: Implications for attitude measurement, change, and strength. Social Cognition, 25(5), 657-686.

Petty, R. E., \& Cacioppo, J. T. (1986). The elaboration likelihood model of persuasion. Advances in experimental social psychology, 19, 123-205.

Rosenkrantz, P. S., \& Crockett, W. H. (1965). Some factors influencing the assimilation of disparate information in impression formation. Journal of Personality and Social Psychology, 2(3), 397-402.

Rydell, R. J., McConnell, A. R., Mackie, D. M., \& Strain, L. M. (2006). Of two minds: Forming and changing valence-inconsistent implicit and explicit attitudes. Psychological Science, 17(11), 954-958.

Sansom-Daly, U. M., \& Forgas, J. P. (2010). Do blurred faces magnify priming effects? The interactive effects of perceptual fluency and priming on impression formation. Social Cognition, 28(5), 630-640.

Skowronski, J. J., \& Carlston, D. E. (1989). Negativity and extremity biases in impression formation: A review of explanations. Psychological bulletin, 105(1), 131-142.

Walther, E., Gawronski, B., Blank, H., \& Langer, T. (2009). Changing likes and dislikes through the back door: The US-revaluation effect. Cognition and Emotion, 23(5), 889-917. 
45 RUNNING HEAD: The Independent Effect of CO-OCCURRENCE

Walther, E., Langer, T., Weil, R., \& Komischke, M. (2011). Preferences surf on the currents of words: Implicit verb causality influences evaluative conditioning. European Journal of Social Psychology, 41(1), 17-22.

Walther, E., Weil, R., \& Langer, T. (2011). Why do we like the iPhone? The role of evaluative conditioning in attitude formation. Social and Personality Psychology Compass, 5(7), 473-486.

Wishner, J. (1960). Reanalysis of "impressions of personality". Psychological Review, 67(2), 96-112.

Zajonc, R. B. (1968). Attitudinal effects of mere exposure. Journal of Personality and Social Psychology, 9, 1-27.

Zanon, R., De Houwer, J., Gast, A., \& Smith, C. T. (2014). When does relational information influence evaluative conditioning?. The Quarterly Journal of Experimental Psychology, 67(11), 2105-2122. 